\title{
Increased hyaluronan production in the glomeruli from diabetic rats: a link between glucose-induced prostaglandin production and reduced sulphated proteoglycan
}

\author{
P. Mahadevan, R. G. Larkins, J. R. E. Fraser, A. J. Fosang, M. E. Dunlop \\ Department of Medicine, University of Melbourne, Royal Melbourne Hospital, Parkville, Victoria, Australia
}

Summary Exposure in vivo or in vitro to elevated glucose increases production of vasoactive prostaglandins by glomeruli and mesangial cells. This study aimed to determine whether this increased prostaglandin production could provide a link with later structural changes in diabetic nephropathy. Glomerular cores were prepared from control rats and streptozotocin-diabetic rats ( 3 weeks' duration). Over $24 \mathrm{~h}$ in culture hyaluronan production from diabetic glomerular cores was higher than production from control glomerular cores whether maintained in $5.6 \mathrm{mmol} / \mathrm{l}$ glucose $(105.6 \pm 15.5 \mathrm{vs} 53.6 \pm 8.5 \mathrm{ng}$ hyaluronan per 250 glomerular cores, $p<0.001$ ); in $25 \mathrm{mmol} / 1$ glucose $(149.3 \pm 34.8$ vs $62.7 \pm 7.8 \mathrm{ng}$ hyaluronan per 250 glomerular cores, $p<0.01$ ); or in $45 \mathrm{mmol} / \mathrm{l}$ glucose $(176.8 \pm 23.3$ vs $102.0 \pm 17.9 \mathrm{ng}$ hyaluronan per 250 glomerular cores, $p<0.01$ ). At $5.6 \mathrm{mmol} / \mathrm{l}$ glucose, exposure in vitro to prostaglandin $E_{2}$ caused an increase in hyaluronan production [maximal at $10^{-9} \mathrm{~mol} / 1$ prostaglandin $\mathrm{E}_{2}, 237 \pm 19$ vs $42 \pm 4$, ng hyaluronan per 250 glomerular cores, $p<0.001$ (control) and $195 \pm 7$ vs $103 \pm 5$, ng hyaluronan per 250 glomerular cores, $p<0.001$ (diabetic) ]. In both control and diabetic glomerular cores hyaluronan production was reduced significantly by the cyclooxygenase inhibitor indomethacin $\left(10^{-5} \mathrm{~mol} / \mathrm{l}\right)$ $[24.7 \pm 3.33$ vs $40.25 \pm 4.11 \mathrm{ng}$ hyaluronan per 250 glomerular cores, $p<0.05$ (control) and $36.5 \pm 6.25$ vs
$118.0 \pm 22.6, p<0.01$ (diabetic)]. A direct spectrophotometric microassay was used to determine the concentration of sulphated glycosaminoglycans derived from papain-digested glomerular core proteoglycans. Release of sulphated glycosaminoglycans from diabetic glomerular cores maintained at $5.6 \mathrm{mmol} / \mathrm{l}$ glucose was decreased $[41.9 \pm 1.1$ vs $54.0 \pm 1.0 \mu \mathrm{g}$ of sulphated glycosaminoglycans (chondroitin sulphate) per 250 glomerular cores $p<0.01]$. A decrease in sulphated glycosaminoglycans was also shown from control glomerular cores maintained at $25 \mathrm{mmol} / 1$ glucose. At this glucose concentration, addition of exogenous hyaluronan or prostaglandin $\mathrm{E}_{2}$ significantly reduced sulphated glycosaminoglycans from control and diabetic glomerular cores. It is concluded that increased prostaglandin production secondary to high glucose environment can lead to an increased glomerular hyaluronan synthesis. This can substantially affect the levels of sulphated glycosaminoglycans in the extracellular matrix. We propose that these effects provide a possible link between the initial biochemical consequences of hyperglycaemia and later structural changes seen in the glomerulus in diabetes. [Diabetologia (1995) 38: 298-305]

Key words: Hyaluronan, prostaglandin, sulphated proteoglycan, glycosaminoglycan, mesangial cell.
Received: 19 July 1994 and in revised form: 5 October 1994

Corresponding author: Dr. M.Dunlop, University of Melbourne, Department of Medicine, Royal Melbourne Hospital, Parkville, Victoria 3050, Australia
Abbreviations: PG, Prostaglandins; GC, glomerular cores; STZ-D, streptozotocin diabetes; GAG, sulphated glycosaminoglycans; PDGF, platelet derived growth factor; $\mathrm{PGE}_{2}$, prostaglandin $\mathrm{E}_{2}$; STZ, streptozotocin; HSPG, heparan sulphate proteoglycan; HA, hyaluronan. 
An increase in glomerular and mesangial cell prostaglandin (PG) production in experimental diabetes has been demonstrated by many means [1-4]. We, and others, have shown that a glucose concentrationdependent production of prostaglandin observed early in the course of experimental diabetes may arise from an increased supply of arachidonic acid following raised phospholipase $A_{2}$ activity [5-11]. Increased activity of phospholipase $A_{2}$ appears to be secondary to the stimulation of protein kinase $\mathrm{C}$ activity following de novo diacylglycerol synthesis from glycolytic intermediates [8, 10-12]. Prostaglandins are considered to contribute to renal vasodilatory hyperfunction and hyperfiltration seen in early diabetes $[3,4,13]$. However, a possible effect of prostaglandins on the structure of glomeruli, including modification of extracellular matrices and, in particular, a reduction in the content of sulphated proteoglycans has not been examined. Reduction of sulphated proteoglycans is believed to contribute to loss of renal charge and selective permeability in the glomerulus [14-19]. Studies in other tissues have shown that the synthesis of hyaluronan, a non-sulphated glycosaminoglycan, is increased following exposure to prostaglandins in vitro [20-23]. Hyaluronan is a major matrix polysaccharide with repeating disaccharide units of glucuronic acid and n-acetylglucosamine. It is synthesised on the inner side of the plasma membrane, by the enzyme hyaluronan synthetase, and extruded directly into the extracellular space to form a poly-disperse, high molecular weight expanded coil [24]. Hyaluronan may be found as free glycosaminoglycan or as part of complex matrix proteoglycan structures and may attach to the cell surface via specific hyaluronan binding proteins [25]. By binding to specific proteins in the matrix, hyaluronan has also been shown to have a role in tissue stability and structure, being involved in tissue repair and remodelling [26]. In fibroblasts hyaluronan synthesis is promoted by platelet-derived growth factor (PDGF) (via the B-type PDGF receptor), epidermal growth factor, basic fibroblast growth factor and transforming growth factor $\beta 1$ [27]. Hyaluronan synthetase activity, measured by the incorporation of ${ }^{14} \mathrm{C}$-glucuronic acid from UDP- ${ }^{14} \mathrm{C}$-glucuronic acid into polymeric hyaluronan, is increased by serum factors, insulin-like growth factor I, various nucleotides, prostaglandin $\mathrm{E}_{2}\left(\mathrm{PGE}_{2}\right)$, cyclic AMP and theophylline [20, 28]. Furthermore, hyaluronan inhibits sulphated glycosaminoglycan (GAG) synthesis and accumulation of newly synthesised proteoglycans in chondrocytes [29-32]. We considered it possible that hyaluronan could provide a link between the increased synthesis of prostaglandins and the reduction of sulphated proteoglycan described in many investigations of the diabetic glomerulus. In the present study we have used a sensitive ligand-binding assay for hyaluronan [33], which avoids the differences in specific activity of precursors for hyaluronan disaccharides, which may result when techniques based on incorporation of radioactive-labelled precursors are used to assess hyaluronan synthesis at high glucose concentrations. We examined hyaluronan synthesis in glomerular preparations in response to sustained glucose exposure and to exogenous $\mathrm{PGE}_{2}$ in vitro and describe its increased production under these conditions and in glomerular preparations from diabetic rats. We have demonstrated a concomitant decrease in sulphated proteoglycans and propose that this may be mediated by the prostaglandin-induced increase in extracellular hyaluronan.

\section{Materials and methods}

Induction of diabetes. Diabetes was induced in 200-g male Sprague Dawley rats with a single intraperitoneal injection of streptozotocin (STZ), $65 \mathrm{mg} / \mathrm{kg}$ mody weight in $100 \mathrm{mmol} / 1 \mathrm{ci}-$ trate buffer, $\mathrm{pH}$ 4.0. Control animals received citrate buffer alone. Assessed by glycosuria, rats became diabetic within $48 \mathrm{~h}$ of STZ administration and remained consistently glycosuric for the 3 weeks preceding the study.

Preparation and culture of glomerular cores. Glomeruli were isolated from kidney cortices of control and diabetic animals by serial sieving and centrifugation and were digested with collagenase, to obtain glomerular cores enriched in mesangial cells as described previously [34]. In these preparations epithelial denudation was confirmed by lack of staining for cytokeratin (epithelial cells). As shown previously [35] a diffuse positive staining for Factor VIII (endothelial cells) and for intermediate filaments (mesangial cells) indicated an approximate $2: 1$ mesangial cell enrichment in the glomerular cell clusters (cores) formed, with no apparent difference between glomerular cores from control and STZ-diabetic animals. For each experiment, glomerular cores from 10-18 animals were pooled and an aliquot of glomerular cores transferred to a micro-haematocrit tube and counted manually. Two hundred and fifty glomerular cores, containing $15.7 \pm 1.2 \mu \mathrm{g}$ protein (control) and $15.9 \pm 1.0 \mu \mathrm{g}$ protein (STZ-diabetic) (no significant difference in protein content, estimated over 12 experiments) were suspended in $0.5 \mathrm{ml}$ of Dulbecco's modified Eagle's medium (DMEM) containing $5.6 \mathrm{mmol} / 1$ glucose and supplemented with $5 \%$ fetal bovine serum, penicillin $(100 \mathrm{U} / \mathrm{ml})$ and streptomycin $(100 \mu \mathrm{U} / \mathrm{ml})$ and were maintained in an atmosphere of $5 \% \mathrm{CO}_{2}$ in air with additions to modify the concentration of glucose, prostaglandin $\mathrm{E}_{2}$ and hyaluronan as shown. Where indicated, mannitol was added to compare glucose supplementation under conditions of equal osmolality. At the completion of incubations, medium was collected for determination of hyaluronan and sulphated glycosaminoglycan concentration. Glomerular core cell viability was determined by trypan blue exclusion at this time.

Ligand binding assay of hyaluronan. A radiometric binding assay based on a specific hyaluronan binding protein (HABP) isolated from bovine cartilage was used to determine hyaluronan released to the culture medium by glomerular cores [33]. Preliminary experiments established that the culture medium contained $83 \pm 7 \%$ of the hyaluronan produced by the cell and that this was unchanged by STZ-diabetes [ $87 \pm 8 \%$ ]. Hyaluronan was allowed to bind ${ }^{125}$-l-labelled HABP in solution for 
$60 \mathrm{~min}$. Subsequently, unbound ${ }^{125}$-I-HABP was quantitated following incubation with hyaluronan covalently coupled to sepharose and separation by centrifugation. The concentration of hyaluronan was calculated from a standard curve prepared from purified avian (rooster comb) hyaluronan [33].

Dye-binding assay for sulphated glycosaminoglycans. Glycosaminoglycans were obtained from glomerular core preparations (culture medium and cell layer) by digestion with papain. After incubation, the medium and cell layers were separated and each was digested with papain $(40 \mathrm{U} / \mathrm{ml})$ in $20 \mathrm{mmol} / \mathrm{l}$ phosphate buffer, $\mathrm{pH} 6.8$ containing $10 \mathrm{mmol} / \mathrm{l} \mathrm{cy}-$ steine, $1 \mathrm{mmol} / \mathrm{l} \mathrm{EDTA}$ and $2 \mathrm{mmol} / \mathrm{l}$ dithiothrietol at $60^{\circ} \mathrm{C}$ for $2 \mathrm{~h}$, in order to release sulphated GAG chains from proteoglycan core proteins. Sulphated glycosaminoglycan content was assayed by a modification [36] of a direct spectrophotometric microassay [37]. This assay is based on the metachromatic shift in adsorption maximum which occurs at $590 \mathrm{~nm}$ when 1,9 dimethyl methylene blue complexes with sulphated glycosaminoglycans and uses purified whale chondroitin 4-sulphate as a standard sulphated GAG. Hyaluronan, which is non-sulphated is not detected with this assay technique.

\section{Materials}

Streptozotocin, collagen (Type V, from Clostridium hystolyticum ), prostaglandin $\mathrm{E}_{2}$, papain (EC 3.4.22.2) and chondroitin 4-sulphate were from Sigma Chemical Co. (St Louis, Mo., USA). Microhaematocrit tubes were purchased from Clay Adams (Parsippany, N.J., USA). Dulbecco's modified Eagle's medium (DMEM) and fetal bovine serum were from CSL Ltd (Melbourne, Australia). Penicillin and streptomycin were from ICN Biomedicals (Sydney, Australia). 1,9-dimethyl methylene blue was from SERVA Fine Biochemica (Heidelberg, Germany). Hyaluronan assay kit (Pharmacia HA test) was from Kabi Pharmacia Diagnostics AB (Uppsala, Sweden). Purified bovine synovial hyaluronan was a generous gift from $\mathrm{Dr}$. Ö. Wik to JREF.

\section{Statistical analysis}

Results are shown as mean \pm SEM with the number of experimental determinations ( $n$ ). Statistical comparisons were made where indicated by use of Student's $t$-test (un-paired).

\section{Results}

Production of hyaluronan can be shown in the medium from glomerular cores maintained in culture for $24 \mathrm{~h}$. When maintained for this time at $5.6 \mathrm{mmol} / 1 \mathrm{glu}-$ cose there is a significantly increased production from glomerular cores obtained from STZ-diabetic animals (Fig.1 A). This significant difference between control and STZ-derived GC was maintained when the glucose concentration was raised over the $24-\mathrm{h}$ culture period to $25 \mathrm{mmol} / 1$ or $45 \mathrm{mmol} / 1$ (Fig. $1 \mathrm{~B}$ ). Addition of mannitol to correct to conditions of equal osmolality was without any effect on hyaluronan production over that time (data not shown).

The effect on control cultures of raising the glucose concentration from $5.6 \mathrm{mmol} / 1$ to $25 \mathrm{mmol} / \mathrm{l}$ was
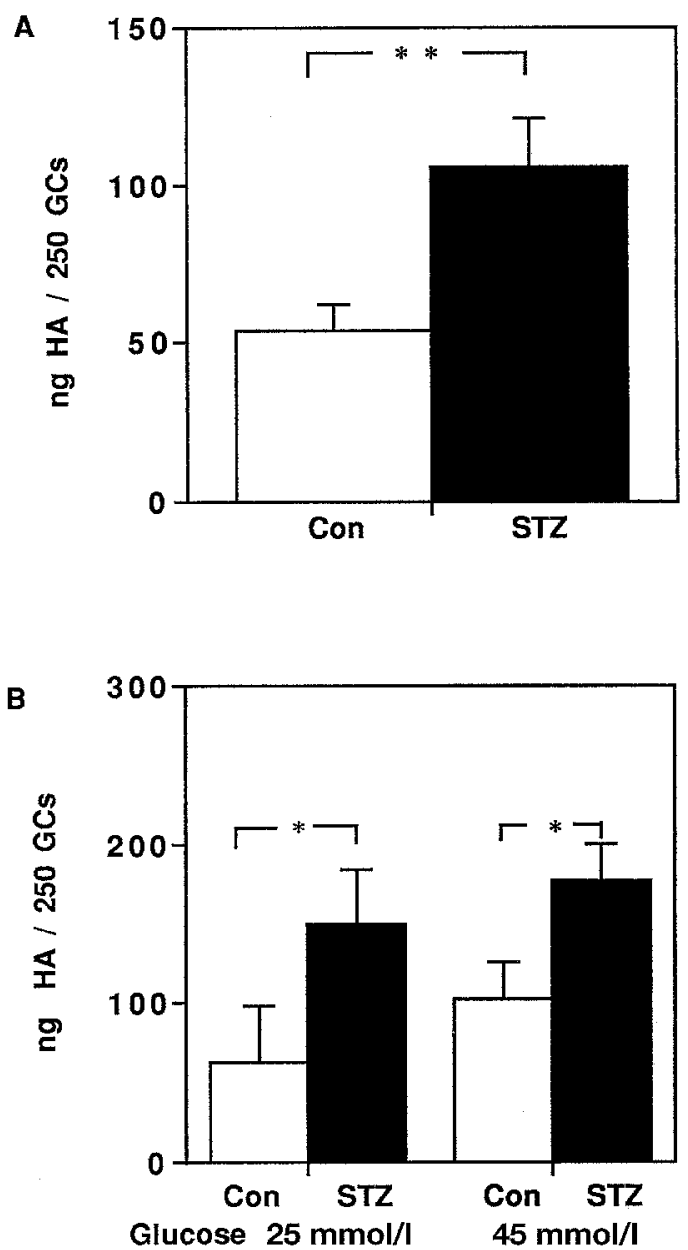

Fig.1 A, B. Hyaluronan (HA) present in culture medium of control and STZ derived glomerular cores following a 24 -h incubation at $5.6 \mathrm{mmol} / 1$ glucose (A) and following incubation at $25 \mathrm{mmol} / \mathrm{l}$ and $45 \mathrm{mmol} / /$ glucose for $24 \mathrm{~h}(\mathbf{B})$. Values are expressed as mean \pm SEM (for 9 experiments $\mathbf{1 A}$ and 8 experiments 1B). Significant difference from control is indicated by $* p<0.01$ and $* * p<0.001$

investigated further over time, to determine whether hyaluronan production was maintained over a continued culture. A glucose-induced increase in hyaluronan production was maintained over $96 \mathrm{~h}$ of culture (Fig. 2). Over the first 24 and $48 \mathrm{~h}$ in culture there was an increase in the production of hyaluronan in the presence of raised glucose levels. At these times the glomerular cores are predominantly non-adherent, retaining much of the intra-glomerular association of cells. By 72 and $96 \mathrm{~h}$, cells are substantially adherent and this may be causal in the marked increase in hyaluronan production seen at both 5.6 and $25 \mathrm{mmol} / \mathrm{l}$ glucose. However, even at the elevated level of hyaluronan seen at later culture times, a significant increase in hyaluronan production is seen with raised glucose concentrations.

The effect of exogenous prostaglandin addition on hyaluronan production was investigated over $24 \mathrm{~h}$ in culture. The results show that hyaluronan produc- 


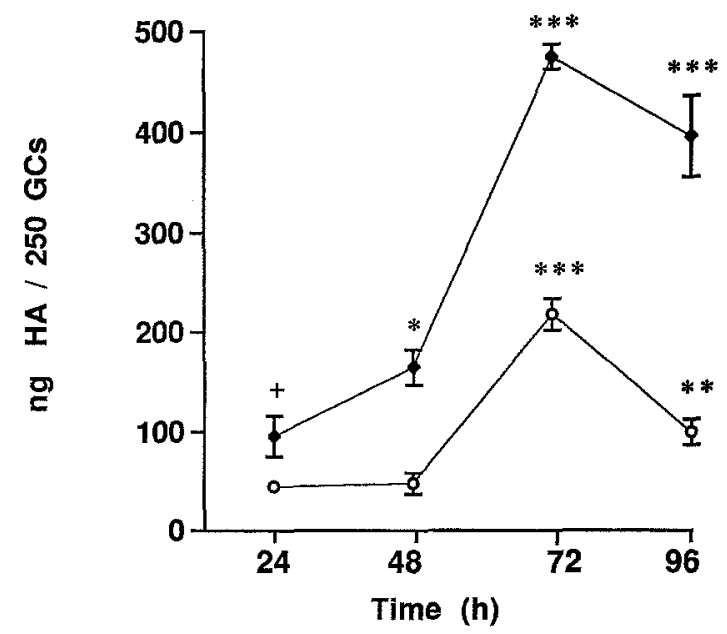

Fig. 2. Time course of hyaluronan production by control glomerular cores. Hyaluronan production from control glomerular cores was determined over 24 -h incubation periods for $24 \mathrm{~h}$ to $96 \mathrm{~h}$ at $5.6 \mathrm{mmol} / 1$ glucose $(0)$ and at $25 \mathrm{mmol} / 1 \mathrm{glu}-$ cose concentration $(\bullet)$. The values are expressed as ng of hyaluronan (HA) produced per 250 glomerular cores and are shown as mean \pm SEM for six experiments. Significant difference from control $\mathrm{GC}$ at $5.6 \mathrm{mmol} / \mathrm{l}$ glucose is indicated by ${ }^{+} p<0.01$ and from $24 \mathrm{~h}$ production at $5.6 \mathrm{mmol} / \mathrm{l}$ or $25 \mathrm{mmol} / \mathrm{1}$ glucose by $* p<0.01, * * p<0.001$ and $* * * p<0.0001$

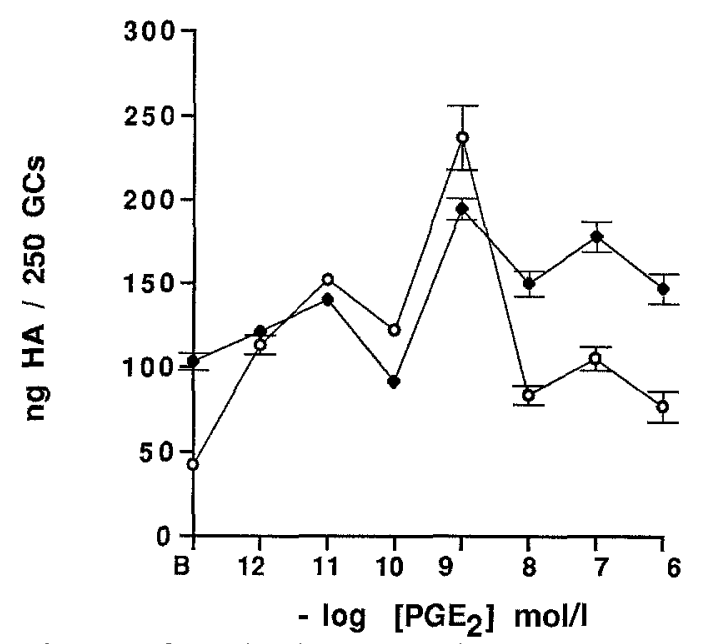

Fig.3. Effect of $P G E_{2}$ on hyaluronan production. Effect of $\mathrm{PGE}_{2}\left(10^{-12}\right.$ to $\left.10^{-6} \mathrm{~mol} / \mathrm{l}\right)$ on hyaluronan production was determined in control $(O)$ and STZ-derived $(\bullet)$ glomerular cores following an incubation for $24 \mathrm{~h}$ at $5.6 \mathrm{mmol} / \mathrm{l}$ glucose. The values are expressed as ng of hyaluronan (HA) produced per 250 glomerular cores and are shown as mean \pm SEM for four experiments. Significant differences are indicated in the text

tion was significantly increased in a concentration-dependent manner following exposure of glomerular cores to $\mathrm{PGE}_{2}$ for $24 \mathrm{~h}$. At the lowest concentration tested, $10^{-12} \mathrm{~mol} / 1$, a significant difference in hyaluronan production $(p<0.0001)$ was apparent in control cores (Fig. 3). In these preparations the response to increasing $\mathrm{PGE}_{2}$ concentrations in culture was bellshaped, with maximum effect seen at $10^{-9} \mathrm{~mol} / \mathrm{l}$

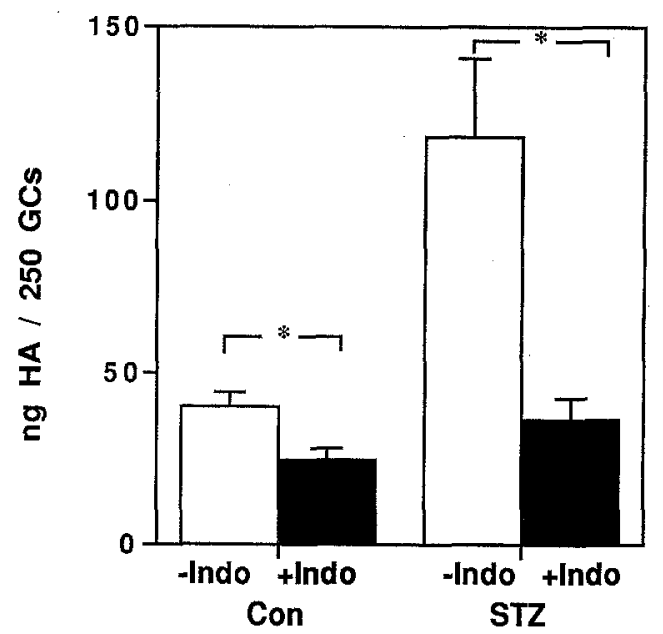

Fig. 4. Effect of cyclooxygenase inhibition on hyaluronan production. Glomerular cores from control and STZ diabetic rats were incubated with indomethacin (Indo) $\left(10^{-5} \mathrm{~mol} / \mathrm{l}\right)$ for $24 \mathrm{~h}$ at $5.6 \mathrm{mmol} / 1$ glucose and hyaluronan production determined. The values are expressed as ng of hyaluronan (HA) produced per 250 glomerular cores (mean \pm SEM for four experiments). Significant difference from basal production is indicated by $* p<0.01$

$\mathrm{PGE}_{2}$. A response to $\mathrm{PGE}_{2}$ could also be shown in glomerular cores from STZ-diabetic animals (Fig. 3). However, in comparison with control glomerular cores, the concentration response was more variable and an optimal concentration less well defined, although a significant increase was observed also at $10^{-9} \mathrm{~mol} / 1 \mathrm{PGE}_{2}(p<0.0001)$.

In both control and STZ-derived glomerular cores hyaluronan production was inhibited significantly by the presence of the cyclooxygenase inhibitor indomethacin $\left(10^{-5} \mathrm{~mol} / \mathrm{l}\right)$ (Fig. 4). Significantly, the elevated production of hyaluronan from STZ-derived cores was reduced so that no difference was seen between control and STZ-derived cores in the presence of indomethacin. This finding was confirmed with two structurally dissimilar cyclooxygenase inhibitors, mefenamic acid and flufenamic acid (data not shown), suggesting that endogenous prostaglandin contributes to increased hyaluronan production.

The concentration of sulphated glycosaminoglycans derived from papain-digested glomerular core proteoglycans was determined. In an initial series of four experiments performed at $5.6 \mathrm{mmol} / \mathrm{l}$ glucose, total sulphated glycosaminoglycan production (glomerular cells + medium) from STZ-D glomerular cores was significantly reduced when compared to control $(53.1 \pm 4.1$ vs $70.3 \pm 5.0 \mu \mathrm{g}$ chondroitin sulphate per 250 glomerular cores, $p<0.05$ ). In these experiments it was shown further that the sulphated glycosaminoglycans from proteoglycans released into the medium by control glomerular cores was $82 \pm$ $2 \%$ of total sulphated glycosaminoglycans and that from STZ-D glomerular cores was $86 \pm 3 \%$ (NS) and in subsequent experiments the concentration of 

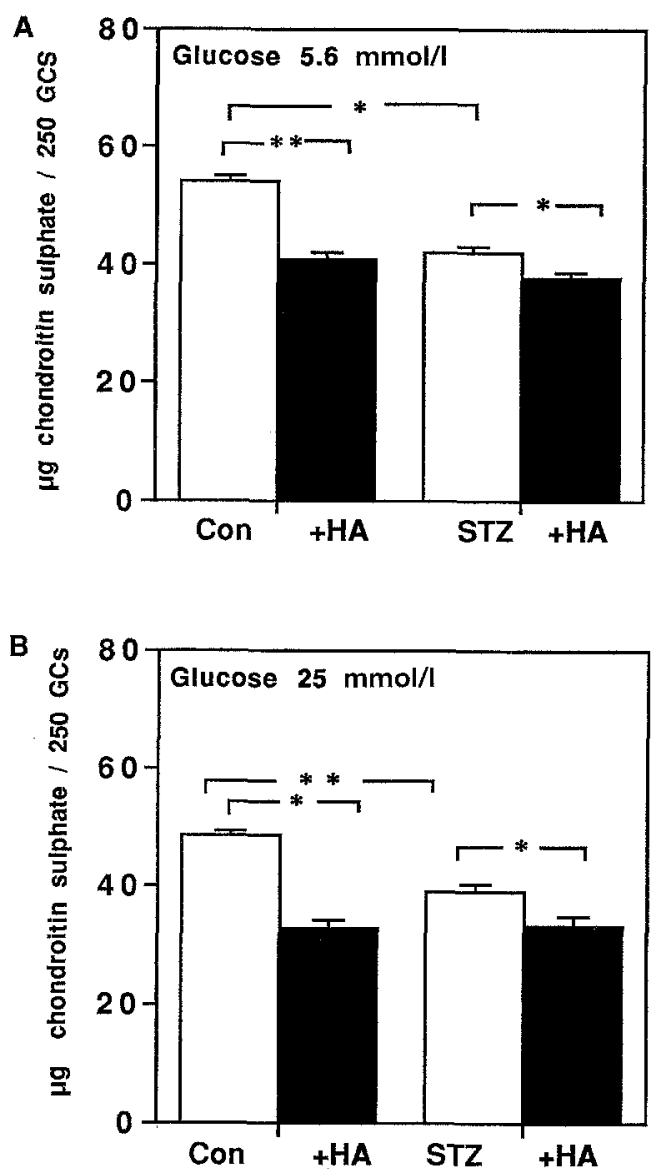

Fig.5 A, B. Determination of sulphated glycosaminoglycans and effect of hyaluronan in glomerular cores. The concentration of sulphated glycosaminoglycans released into the medium by control and STZ derived glomerular cores was determined following incubation at $5.6 \mathrm{mmol} / \mathrm{l}$ glucose $(\square, \mathbf{A})$ or $25 \mathrm{mmol} / 1$ glucose $(\square, \mathbf{B})$ for $24 \mathrm{~h}$. The effect of hyaluronan was determined by incubation of glomerular cores from control and STZ-diabetic rats with $250 \mathrm{ng} / \mathrm{ml}$ high molecular weight hyaluronan $\left(\mathrm{M}, 5 \times 10^{6} \mathrm{Da}\right)$ for $24 \mathrm{~h}$ at $5.6 \mathrm{mmol} / \mathrm{l}$ and $25 \mathrm{mmol} / 1$ glucose ( $\mathbf{E}, \mathbf{A}$ and $\mathbf{B}$, respectively). The values are quantitated as $\mu \mathrm{g}$ of chondroitin sulphate per 250 glomerular cores and expressed as mean \pm SEM. Significant difference from the control value and the value in the absence of hyaluronan is indicated by $* p<0.01$ and $* * p<0.001$, (for $18-34$ experiments for $\mathbf{A}$ and 8 experiments for $\mathbf{B}$ )

glycosaminoglycans in the culture medium following incubations with and without supplemented glucose, hyaluronan or $\mathrm{PGE}_{2}$ was determined.

Sulphated glycosaminoglycans present in the medium, from glomerular cores maintained for $24 \mathrm{~h}$ in culture at 5.6 and $25 \mathrm{mmol} / 1$ glucose are shown in Figure 5. The concentration was decreased in STZ-derived glomerular cores at both 5.6 and $25 \mathrm{mmol} / \mathrm{l} \mathrm{glu-}$ cose. Further, at both glucose concentrations, addition of hyaluronan, $250 \mathrm{ng} / \mathrm{ml}$ as a high molecular weight polymer of $5 \times 10^{6} \mathrm{Da}$, decreased sulphated glycosaminoglycan levels significantly in both control and STZ-derived glomerular cores (Fig.5). When cultured with $\mathrm{PGE}_{2}\left(10^{-9} \mathrm{~mol} / \mathrm{l}\right)$ at $25 \mathrm{mmol} / \mathrm{l}$ glucose, there was a significant reduction in sulphat-

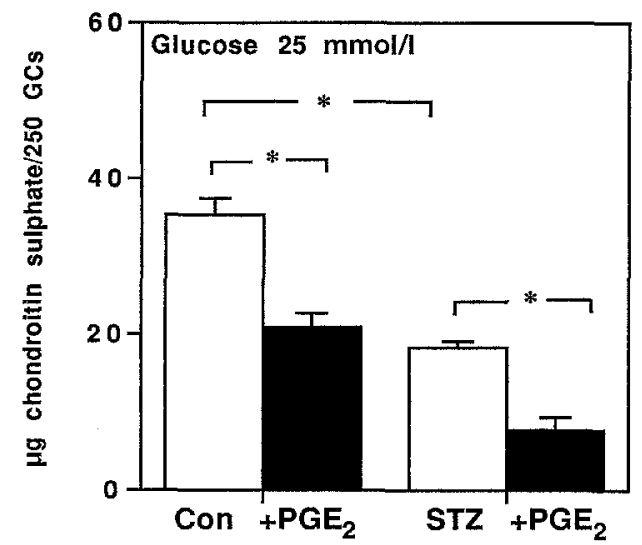

Fig. 6. Effect of $P G E_{2}$ on sulphated glycosaminoglycans. The concentration of sulphated glycosaminoglycans released into the medium over $24 \mathrm{~h}$ was determined, following an incubation of control and STZ-derived glomerular cores with $\mathrm{PGE}_{2}$ $\left(10^{-9} \mathrm{~mol} / \mathrm{l}\right.$, at $25 \mathrm{mmol} / 1$ glucose. The values are quantitated as $\mu \mathrm{g}$ of chondroitin sulphate per 250 glomerular cores and expressed as mean \pm SEM for five experiments. Significant difference from basal value and the value in the absence of $\mathrm{PGE}_{2}$ is indicated by $* p<0.001$

ed glycosaminoglycans from both control and STZD glomerular cores (Fig. 6).

In a separate series of three experiments the effect of indomethacin $\left(10^{-5} \mathrm{mmol} / \mathrm{l}\right)$ on sulphated glycosaminoglycans was investigated in control and STZ-D glomerular cores incubated for $24 \mathrm{~h}$ at $25 \mathrm{mmol} / \mathrm{l} \mathrm{glu}-$ cose. A significant increase in medium sulphated glycosaminoglycans was seen from incubations in which indomethacin was included $(44.1 \pm 1.6$ to $50.2 \pm$ $3.2 \mu \mathrm{g}$ chondroitin sulphate per 250 glomerular cores (control), $p<0.05$ and $25.7 \pm 1.6$ to $32.4 \pm 3.1 \mu \mathrm{g}$ chondroitin sulphate per 250 glomerular cores (STZD), $p<0.05)$.

\section{Discussion}

This study demonstrates that STZ-diabetic rats have increased production of hyaluronan from glomerular cores which are rich in mesangial cells. We have shown that exposure of glomerular cores to high glucose stimulates hyaluronan production. Two potential mechanisms can be postulated for the glucose-mediated increase in hyaluronan synthesis. Glucose may increase the UDP-precursor pools, providing more UDP-n-acetylglucosamine and UDP-glucuronic acid, for hyaluronan production. Diabetes may additionally modify this utilisation of glucose via augmentation of the pentose phosphate pathway [38], enhancing this effect. Alternatively, glucose may mediate increased hyaluronan synthesis by the cellular pathway in which increased de novo synthesis of diacylglycerol from glucose-derived trioses provides a mechanism for protein kinase $\mathrm{C}$-dependent activation of phospholipase $\mathrm{A}_{2}$ with increased production of cellular 
arachidonic acid and subsequent to this an increased prostaglandin production [12]. The diabetic glomerulus has been shown consistently to have increased prostaglandin production [1-5]. The present study demonstrates that exogenous $\mathrm{PGE}_{2}$ stimulates hyaluronan synthesis by glomerular cores. Exogenous prostaglandins have been shown to potentiate hyaluronan synthesis in other cell culture systems, including human synovial cells [22], rat fibroblasts [20] and rabbit pericardial cells [23]. In these latter cells, Honda and co-workers [23] have shown that a cyclic AMP-dependent protein kinase A-mediated phosphorylation is involved in increased hyaluronan production. In that study exogenous arachidonic acid stimulated hyaluronan synthesis, supporting a link between prostaglandin production and cyclic AMP-mediated hyaluronan production. As with studies in other cell types [22, 39], the inhibitory effect of indomethacin on hyaluronan in the present study confirms the involvement of endogenous prostaglandin synthesis.

In various tissues or cell culture systems stimulation of hyaluronan synthesis may be induced by fetal bovine serum [20], epidermal growth factor [30, 40], oestrogen [41], interleukin 1 [42], retinoic acid [43], vanadate [44], insulin-like growth factor 1 [28], platelet-derived growth factor [27], transforming growth factor $\beta$, phorbol ester [27, 44], or polyinosine and polycytidine inducers of interferon [22]. Thus, multiple signalling pathways may contribute to stimulation of endogenous hyaluronan synthesis. These may be interrelated and also determined by cell type. Recently it has been reported that both tyrosine phosphorylation and protein kinase C-dependent events are involved in the stimulation of hyaluronan synthetase activity by PDGF-BB in human mesothelial cells [44]. A bacterial hyaluronan synthetase enzyme has recently been cloned and sequenced and shown to have a potential tyrosine kinase phosphorylation site [45]. However, the molecular mechanism(s) for stimulation of hyaluronan synthesis are not currently known.

Recent studies of macrovascular disease in diabetes have shown that hyaluronan may play a role in generalised diabetic angiopathy. Accumulation of hyaluronan has been reported by Heickendorff et al. [46] in the tunica media of the aorta of diabetic patients and suggests a role for hyaluronan associated changes in the extracellular matrix of the arterial wall. A role in microvascular complications has not been considered previously. In the diabetic kidney much of the previous work on proteoglycan content has focussed on the heparan sulphate proteoglycans (HSPG) of the basement membrane in which decreased staining for HSPG $[47,48]$ and decreased sulphate incorporation into HSPG of basement membrane $[15,16]$ have been demonstrated in vitro in glomeruli isolated from diabetic rats. This is thought to give rise to a decreased sulphate: uronate ratio in heparan sulphate proteoglycans of glomerular base- ment membrane isolated from diabetic rats. Elevated glucose concentrations have been shown to decrease the content of basement membrane-associated heparan sulphate in proliferating cultured porcine mesangial cells [19]. An inhibitory effect of hyperglycaemic glucose concentrations on human mesangial cell proteoglycan synthesis was demonstrated by Mason et al. [49]. This is in contrast to a stimulatory effect of diabetes or of raised glucose concentration on the production of other matrix macromolecules in the glomerulus and mesangial cells. We have shown in the present investigation that mesangial cell enriched glomerular cores derived from STZ-diabetic animals have a significant decrease in sulphated glycosaminoglycans.

There is limited information regarding the quantity and character of the proteoglycans of the mesangial matrix. Chondroitin sulphate and dermatan sulphate are present in the mesangial matrix and chondroitin sulphate has been shown to be the major glycosaminoglycan found in proteoglycans localized to the mesangium and is not present in any significant amount in the glomerular basement membrane [49]. Proteoglycans have been shown to interact specifically with other components in the extracellular matrix, such as collagen, fibronectin other proteoglycans, growth factors and cells [50]. These interactions are mediated partly via the negatively charged glycosaminoglycan chains of the proteoglycans, and affect cell binding to matrix and cell proliferation [51-56]. Silbiger et al. [57] have demonstrated that mesangial cells cultured in high glucose produce proteoglycans with a lower negative charge density and have further suggested that this is related to decreased sulphation of the glycosaminoglycan component of proteoglycans.

We have demonstrated in the present study that the presence of hyaluronan significantly reduces sulphated glycosaminoglycans in glomerular cores and have identified a mechanism whereby hyaluronan may be raised in cells exposed to high glucose or in diabetes. The mechanism for the inhibitory action of hyaluronan on sulphated glycosaminoglycans has been investigated in various cell culture models [2932], including articular chondrocytes. Weibkin and Muir [29] have shown that the inhibitory effect of hyaluronan on proteoglycan synthesis results from its interaction with the cell surface. Handley and Lowther [31] demonstrated that hyaluronan reduces glycosaminoglycan chain initiation, either by specifically repressing the activity of the enzyme xylosyl transferase, which plays a key role in initiation of glycosaminoglycan chain synthesis, or by depressing the synthesis of core protein. These effects have not been investigated in the glomerulus. It is of interest that alterations in amount, distribution and sulphation pattern of proteoglycans have been found in non-renal tissues, such as the vasculature, cartilage and liver of animals with induced diabetes [58-60]. 
Measurements of $\mathrm{PGE}_{2}$ production by isolated rat glomeruli $[61,62]$ or the production of $\mathrm{PGE}_{2}$ from individual glomeruli in vivo by micropuncture [63] show a basal production of between 0.57 and 2.2 fmol per glomeruli over $10 \mathrm{~min}$. In the latter study measurement of single nephron glomerular filtration rate in the earliest proximal convolution allows an estimation of glomerular $\mathrm{PGE}_{2}$ concentration in the nanomolar range. Thus, the concentrations of $\mathrm{PGE}_{2}$ found to be effective in the present study are of physiological relevance. The present study shows that elevated prostaglandin production, considered previously to be associated with an early functional effect on vasodilatation and hyperfiltration in diabetes, may also affect the mesangial matrix organization. Specifically, the changes may promote a mesangial matrix with reduced content of sulphated glycosaminoglycans in which interactions with other matrix components are altered [53-56, 59]. The present findings were obtained under diabetic conditions modelled in vitro, and although caution must be exercised in extrapolating to the long-term in vivo situation, they provide a potential link between the biochemical consequences of hyperglycaemia and matrix structural changes seen in the later stages of diabetic nephropathy.

Acknowledgements. This work was supported by grants from the National Health and Medical Research Council of Australia, Diabetes Australia Research Trust, and Juvenile Diabetes Foundation International.

\section{References}

1. Kreisberg JI, Patel PY (1983) The effects of insulin, glucose and diabetes on prostaglandin production by rat kidney glomeruli and cultured glomerular mesangial cells. Prostaglandins Leukotrienes Med 11: 431-432

2. Schambelan M, Blake S, Sraer J, Bens M, Nivez M-P, Wahbe F (1985) Increased prostaglandin production by glomeruli isolated from rats with streptozotocin-induced diabetes mellitus. J Clin Invest 75: 404-412

3. Craven PA, Caines MA, DeRubertis FR (1987) Sequential alterations in glomerular prostaglandin and thromboxane synthesis in diabetic rats: relationship to the hyperfiltration of early diabetes. Metabolism 36: 95-103

4. Esmatjes E, Fernandez MR, Halperin I et al. (1985) Renal hemodynamic abnormalities in patients with short term insulin-dependent diabetes mellitus: role of renal PGs. J Clin Endocrinol Metab 60: 1231-1237

5. Dunlop M, Keogh R, Larkins RG (1993) Fibronectin-induced increase in mesangial cell prostaglandin release: effect of hyperglycemia and PKC inhibition. Diabetes 42: 183-190

6. Craven PA, De Rubertis FR (1989) PKC is activated in glomeruli from streptozotocin diabetic rats: possible mediation by glucose. J Clin Invest 83: 1667-1675

7. Craven PA, Davidson CM, De Rubertis FR (1990) Increase in diacylglycerol mass in isolated glomeruli by glucose from de novo synthesis of glycerolipids. Diabetes 39: $667-674$
8. Dunlop ME, Larkins RG (1990) Persistence in culture of increased de novo synthesis of diacylglycerol, phospholipase $\mathrm{A}_{2}$ activity and prostaglandin production by mesangial cells of diabetic rats. Diabetes [Suppl 1] 39: 189A (Abstract)

9. Ayo SH, Radnik R, Garoni JA, Troyer DA, Kreisberg JI (1991) High glucose increases diacylglycerol mass and activates PKC in mesangial cell cultures. Am J Physiol 261: F571-F577

10. Craven PA, Patterson MC, De Rubertis FR (1988) Role of enhanced arachidonate availability through phospholipase $\mathrm{A}_{2}$ pathway in mediation of increased prostaglandin synthesis by glomeruli from diabetic rats. Diabetes 37: 429-435

11. Williams B, Schrier RW (1993) Glucose-induced protein kinase $C$ activity regulates arachidonic acid release and prostaglandin production by cultured rat glomerular mesangial cells. J Clin Invest 92: 2889-2896

12. DeRubertis FR, Craven PA (1994) Activation of protein kinase $\mathrm{C}$ in glomerular cells in diabetes. Mechanisms and potential links to the pathogenesis of diabetic glomerulopathy. Diabetes 43: 1-8

13. Kasiske BL, O'Donnell MP, Keane WF (1985) Glucose-induced increases in renal hemodynamic function: possible modulation by renal prostaglandins. Diabetes 34: 360-364

14. Cohen MP, Surma ML (1981) [ $\left.{ }^{35} \mathrm{~S}\right]$-sulfate incorporation into glomerular basement membrane glycosaminoglycan is decreased in experimental diabetes. J Lab Clin Med 98: 715-721

15. Brown DM, Klein DJ, Michael AF, Oegema Jr TR (1985) ${ }^{35}$ S-glycosaminoglycan and ${ }^{35} \mathrm{~S}$-glycopeptide metabolism by diabetic glomeruli and aorta. Diabetes 31: 418-425

16. Parthasarathy N, Spiro RG (1982) Effect of diabetes on the glycosaminoglycan component of the human glomerular basement membrane. Diabetes 31: 738-741

17. Cohen MP, Klepser H, Wu V-Y (1988) Undersulphation of glomerular basement membrane heparan sulphate in experimental diabetes and lack of correction with aldose reductase inhibitors. Diabetes 37: 1324-1327

18. Kanwar YS, Farquhar MG (1979) Presence of heparan sulfate in the glomerular basement membrane. Proc Natl Acad Sci USA 76: 1303-1307

19. Olgemöller B, Shwaabe S, Gerbitz KD, Scleicher ED (1992) Elevated glucose decreases the content of a basement membrane associated heparan sulphate proteoglycan in proliferating cultured porcine mesangial cells. Diabetologia 35: 183-186

20. Tomida M, Koyama H, Ono T (1977) Effects of adenosine $3^{\prime}: 5^{\prime}$-cyclic monophosphate and serum on synthesis of hyaluronic acid in confluent rat fibroblasts. Biochem J 162: 539-543

21. Castor W (1974) Connective tissue activation. VII. Evidence supporting a role for prostaglandins and cyclic nucleotides. Connective Tissue Activation 85: 392-402

22. Yaron M, Yaron I, Wiletzki C, Zor U (1978) Interrelationship between stimulation of prostaglandin $\mathrm{E}$ and hyaluronate production by poly (I), poly (C) and interferon in synovial fibroblast culture. Arthritis Rheum 21: 694-698

23. Honda A, Sekiguchi Y, Mori Y (1993) Prostaglandin $E_{2}$ stimulates cyclic AMP-mediated hyaluronan synthesis in rabbit pericardial mesothelial cells. Biochem J 292: 497502

24. Laurent TC (1989) Introduction In: Evered D, Whelan J (eds) The biology of hyaluronan. Wiley Chichester (Ciba Foundation Symposium) 143: 1-5

25. Peach RJ, Hollenbaugh D, Stamenkovic I, Aruffo A (1993) Identification of hyaluronic acid binding site in the extracellular domain of CD44. J Cell Biol 122: 257-264 
26. McGuire PG, Catellot J, Orkin RW (1987) Size-dependent hyaluronate degradation by cultured cells. J Cell Physiol 133: $267-276$

27. Heldin P, Laurent TC, Heldin GH (1989) Effect of growth factors on hyaluronan synthesis in cultured human fibroblasts. Biochem J 258: 919-922

28. Honda A, Iwai T, Mori Y (1989) Insulin-like growth factor I (IGF-I) enhances hyaluronic acid synthesis in rabbit pericardium. Biochem Biophys Acta 1014: 305-312

29. Weibkin OW, Muir H (1977) Synthesis of proteoglycans by suspension and monolayer cultures of adult chondrocytes and de novo cartilage nodules - the effect of hyaluronic acid. J Cell Sci 27: 199-211

30. Mason RM, Crossman MV, Sweeney C (1989) Hyaluronan and hyaluronanbinding proteins in cartilagenous tissues. The biology of hyaluronan. Wiley Chichester (Ciba Foundation Symposium) 143: 107-120

31. Handley CJ, Lowther DA (1986) Inhibition of proteoglycan biosynthesis by hyaluronic acid in chondrocytes in cell culture. Biochim Biophys Acta 444: 69-74

32. Shimazu A, Jikko A, Iwamoto M et al. (1993) Effects of hyaluronic acid on the release of proteoglycan from the cell matrix in rabbit chondrocyte cultures in the presence and absence of cytokines. Arthritis Rheum 36: 247253

33. Brandt R, Hedolf E, Asman I, Bucht A, Tengblad A (1987) A convenient radiometric assay for hyaluronan. Acta Otolar 442: 31-35

34. Dunlop ME, Larkins RG (1990) Insulin-dependent contractility of glomerular mesangial cells in response to angiotensin II, platelet activating factor and endothelin is attenuated by prostaglandin $\mathrm{E}_{2}$. Biochem J 272: 561-568

35. Hassis A, Pidikiti N, Gamero D (1986) Effects of vasoactive peptides on cytosolic calcium in cultured mesangial cells. Am J Physiol 251: F1018-F1028

36. Ratcliffe A, Doherty M, Mairi RN, Hardingham TE (1988) Increased levels of proteoglycan components in the synovial fluids of patients with acute joint disease. Ann Rheum Dis 47: 826-832

37. Farndale RW, Sayers CA, Barrett AJ (1982) A direct spectrophotometric microassay for sulfated glycosaminoglycans in cartilage cultures. Conn Tiss Res 9: 247-248

38. Sochor M, Zaheer Baquer N, McLean P (1979) Regulation of pathways of glucose metabolism in the kidney. The effect of experimental diabetes on the activity of the pentose phosphate pathway and the glucuronate-xylulose pathway. Arch Biochem Biophys 198: 632-646

39. Butler DM, Vitti GF, Leizer T, Hamilton JA (1988) Stimulation of the hyaluronic acid levels of human synovial fibroblasts by recombinant human tumor necrosis factor $\alpha$, tumor necrosis factor $\beta$, interleukin $1 \alpha$ and interleukin $1 \beta$. Arthritis Rheum 31: 1281-1289

40. Hata R, Sunada H, Arai K, Sato T, Ninomiya Y, Nagai Y, Senoo H (1988) Regulation of collagen metabolism and cell growth in cultured skin fibroblasts. Eur J Biochem 173: 261-267

41. Uzuka M, Nakajima K, Ohta S, Mori Y (1980) The mechanism of estrogen-induced increase in hyaluronic acid biosynthesis, with special reference to estrogen receptor in the mouse skin. Biochim Biophys Acta 627: 199-206

42. Postlethwaite AE, Smith GN, Lachman LB et al. (1989) Stimulation of glycosaminoglycan synthesis in cultured human dermal fibroblasts by interleukin 1. J Clin Invest 83: 629-636

43. Prehm P (1980) Induction of hyaluronic acid synthesis in teratocarcinoma stem cells by retinoic acid. FEBS Lett 111: $295-298$
44. Heldin P, Asplund T, Ytterberg D, Thelin S, Laurent T (1992) Characterization of the molecular mechanism involved in the activation of hyaluronan synthetase by platelet derived growth factor in human mesothelial cells. Biochem J 283: 165-170

45. Lansing M, Lellig S, Mausolf et al. (1993) Hyaluronate synthase: cloning and sequencing of the gene from Streptococcus sp. Biochem J 289: 179-184

46. Heickendorff L, Ledet T, Rasmussen LM (1994) Glycosaminoglycans in the human aorta in diabetes mellitus: a study of the tunica media from areas with and without atherosclerotic plaque. Diabetologia 37: 286-292

47. Templeton DM (1989) Retention of glomerular basement membrane-proteoglycans accompanying loss of anionic site staining in experimental diabetes. Lab Invest 61: 202-211

48. Rohrbach R (1986) Reduced content and abnormal distribution of anionic sites (acid proteoglycans) in the diabetic glomerular basement membrane. Virchows Arch B Cell Path 51: 127-135

49. Mason RM, Thomas G, Davies M (1992) Proteoglycan synthesis by human mesangial cells is depressed by hyperglycemic glucose concentrations. Biochem Soc Transactions 20: 20 (Abstract)

50. Hardingham TE, Fosang AJ (1992) Proteoglycans: many forms and many functions. Faseb J 6: 861-870

51. LeBaron RG, Hook A, Esko JD, Gay JS, Hook M (1989) Binding of heparan sulfate to type $\mathrm{V}$ collagen. J Biol Chem 264: 7950-7956

52. Stamatoglou SC, Keller JM (1982) Interactions of cellular glycosaminoglycans with plasma fibronectin and collagen. Biochim Biophys Acta 719: 90-97

53. Schmidt G, Robenek H, Harrach B et al. (1987) Interaction of small dermatan sulfate proteoglycan from fibroblasts with fibronectin. J Cell Biol 104: 1683-1691

54. Pringle GA, Dodd CM (1990) Immunoelectron microscopic localizations of the core protein of decorin near the $\mathrm{d}$ and e bands of tendon collagen fibrils by use of monoclonal antibodies. J Histochem Cytochem 38: 1405-1411

55. Vogel KG, Paulsson M, Heingard D (1984) Specific inhibition of type I and type II collagen fibrillogenesis by the small proteoglycan of tendon. Biochem J 223: 587-597

56. Oldberg A, Ruoslahti E (1982) Interactions between chondroitin sulfate proteoglycan, fibronectin, and collagen. $\mathrm{J}$ Biol Chem 257: 4859-4863

57. Silbiger S, Schlondorff D, Crowley S et al. (1993) The effect of glucose on proteoglycans produced by cultured mesangial cells. Diabetes 42: 1815-1822

58. Sirek OV, Sirek A, Cukerman E (1980) Arterial glycosaminoglycans in diabetic dogs. Blood Vessels 17: 271-275

59. Axellesson I, Lorentzon R, Pita JC (1983) Biosynthesis of rat growth plate proteoglycans in diabetes and malnutrition. Calcif Tissue Int 35: 237-242

60. Kjellen L, Bielefeld D, Hook M (1983) Reduced sulfation of liver heparan sulfate in experimentally diabetic rats. Diabetes 32: 337-342

61. Sraer J, Sraer JD, Chansel D, Russo-Marie F, Kouznetzova B, Ardaillou R (1979) Prostaglandin synthesis by isolated rat renal glomeruli. Mol Cell Endocrinol 16:29-37

62. Schlondorff D, Roczniak S, Satriano JA, Folkert VW (1980) Prostaglandin synthesis by isolated rat glomeruli, effect of angiotensin II. Am J Physiol 239 (Renal Fluid Electrolyte Physiol 8): F486-F459

63. Schlondorff D, Aynedjian HS, Satriano JA, Bank N (1987) In vivo demonstration of glomerular $P G E_{2}$ responses to physiological manipulations and experimental agents. Am J Physiol 252 (Renal Fluid Electrolyte Physiol 21): F717F723 